Check for updates

Cite this: RSC Adv., 2019, 9, 15457

Received 23rd February 2019

Accepted 5th May 2019

DOI: 10.1039/c9ra01379b

rsc.li/rsc-advances

\title{
Preparation of graphene oxide/poly(vinyl alcohol) composite membrane and pervaporation performance for ethanol dehydration
}

\author{
Xue Cheng, ${ }^{a}$ Weibin Cai, (DD *a Xiaohan Chen, ${ }^{\text {a }}$ Zhen Shi ${ }^{\mathrm{a}}$ and Jiding $\mathrm{Li}^{\mathrm{b}}$
}

\begin{abstract}
Although poly(vinyl alcohol) (PVA) membranes are widely used in solvent dehydration by pervaporation, the separation factor is rather limited. Considering this, novel PVA mixed matrix membranes with graphene oxide (GO) nanosheets were prepared. poly(acrylonitrile) ultrafiltration (PAN) membrane was used as support layer. The PVA/GO composite membranes were characterized by Fourier transform infrared spectroscopy, X-ray diffractometry, scanning electron microscopy, thermogravimetric analysis and water contact angle. We also explored the pervaporation performance of the membrane for ethanol dehydration. GO slightly improves the thermal stability and crystallinity of the composite membranes. In addition, the hydrophilicity of the composite membranes is weakened after GO addition, but the crosslinking degree is increased, resulting a significant increase in the separation factor and a certain decrease in the total flux. With the amount of GO addition increases, the total flux of the PVA/GO composite membrane decreases, while the separation factor increases first and then decreases, and the preferred amount of GO addition is $2.0 \mathrm{wt} \%$. Especially, the separation factor of the composite membranes with $2.0 \mathrm{wt} \% \mathrm{GO}$ addition could reach 3 059, which is 16 times higher than PVA membranes, with the corresponding permeability flux is $145 \mathrm{~g} \mathrm{~m}^{-2} \mathrm{~h}^{-1}$.
\end{abstract}

\section{Introduction}

As a renewable energy source, fuel ethanol is the development focus of alternative fuels energy in the world, and it has good economic and social benefits and hopes to partially replace gasoline and diesel. ${ }^{\mathbf{1 , 2}}$ Pervaporation technology (PV) ${ }^{3}$ could separate ethanol-water mixture with high efficiency and low energy consumption, ${ }^{4}$ providing an opportunity for the application of anhydrous fuel ethanol. At present, pervaporation technology has been industrialized in the field of organic solvent dehydration. In 1982, GFT of Germany took the lead in building the world's first pervaporation unit for ethanol dehydration via cross-linked poly(vinyl alcohol) (PVA) membranes. PVA $^{5,6}$ is non-toxic, inexpensive and biodegradable watersoluble polymers with hydroxyl groups in molecular chain and strict linear structures. It has high hydrophilicity and good membrane forming property, which is used for organic solvents dehydration and exhibits superior separation performance. However, PVA is poor in water resistance and tends to swell excessively in aqueous solution, which makes it weak in mechanical strength and thermal stability, resulting in sharp drops in separation performance. Table 1 contains some key data on the PVA membrane for organic solvents dehydration by

${ }^{a}$ School of Chemical and Environmental Engineering, China University of Mining and Technology, Beijing 100083, China. E-mail: caiweibin2000@126.com

${ }^{b}$ Department of Chemical Engineering, Tsinghua University, Beijing 100084, China pervaporation. As can be seen from Table 1, for the ethanolwater system, the separation factor of PVA membranes with different cross-linking methods was rather limited. To solve the problem, various modification techniques such as blending, grafting, and crosslinking are employed. Among them, doping inorganic nanomaterials have become an important research direction, polymer nanocomposites membranes were prepared by PVA with nano-SiO ${ }_{2},{ }^{17,18} \mathrm{NaA}$ zeolite, ${ }^{19}$ nano- $\mathrm{TiO}_{2},{ }^{20}$ carbon nitride, ${ }^{21,22} \mathrm{Ag}^{23,24}$ and other inorganic nanomaterials. Arif et $a{ }^{17}{ }^{17}$ synthesized PVA/silica membranes by sol-gel derived route for application in pervaporation of isopropanol-water mixture. The chemically cross-linked composite membrane prepared showed improved performance concerning flux and selectivity when compared to the pristine PVA membrane. The addition of silica changes semi-crystalline PVA to an amorphous polymer which favoured diffusion of the water molecule to permeate through membrane hence flux increases. In the work of Wang et al. ${ }^{21}$ hybrid membranes with excellent water/ ethanol separation performance and superior water channels were fabricated by incorporating g- $\mathrm{C}_{3} \mathrm{~N}_{4}$ nanosheets into a PVA matrix. Due to the strong interfacial interactions between $\mathrm{g}$ $\mathrm{C}_{3} \mathrm{~N}_{4}$ and PVA, the hybrid nanocomposite membranes showed both high swelling resistance and mechanical stability. The total flux and separation factor of the new membrane can reach to $6332 \mathrm{~g} \mathrm{~m}^{-2} \mathrm{~h}^{-1}$, and 30.7 for $90 \mathrm{wt} \%$ ethanol, respectively. Compared with the cross-linked pure PVA membrane $(2337 \mathrm{~g}$ $\mathrm{m}^{-2} \mathrm{~h}^{-1}$ and 11.2), the composite membrane could break the 
Table 1 Dehydration of organic solvents using PVA membranes

\begin{tabular}{|c|c|c|c|c|c|c|}
\hline Solution-water mixture (mass ratio) & Membrane & Cross-linker & Flux $\left(\mathrm{g} \mathrm{m}^{-2} \mathrm{~h}^{-1}\right)$ & $\begin{array}{l}\text { Separation } \\
\text { factor }\end{array}$ & Temperature $\left({ }^{\circ} \mathrm{C}\right)$ & Ref. \\
\hline Isopropanol/water (90:10) & PVA & Glutaraldehyde & 40 & 21 & 30 & 7 \\
\hline Isopropanol/water $(80: 20)$ & PVA & Thermally cross-linked & 140 & 40 & 50 & 9 \\
\hline Acetic $\mathrm{acid} /$ water $(90: 10)$ & PVA & Glutaraldehyde & 100 & 9 & 30 & 10 \\
\hline Acetic acid/water $(90: 10)$ & PVA & - & 37.1 & 11.61 & 45 & 11 \\
\hline Ethanol/water (azeotrope) & PVA & - & 120 & 10 & 60 & 13 \\
\hline Ethanol/water $(90: 10)$ & PVA & Dimethylolurea & 120 & 115 & 60 & 14 \\
\hline Ethanol/water $(90: 10)$ & PVA & Glutaraldehyde & 95 & 77.3 & 30 & 15 \\
\hline Ethanol/water $(80: 20)$ & PVA & Thermally cross-linked & 183 & 15.5 & 50 & 9 \\
\hline Ethanol/water (95:5) & PVA (GFT 1510/2510) & Malic acid & 600 & 258 & 60 & 16 \\
\hline
\end{tabular}

"trade-off effect" effectively. In the study of Premakshi et al. ${ }^{25}$ the silver nanoparticles were in situ prepared before crosslinking PVA matrix by reducing of silver ions using sodium borohydride. The membranes were under go pervaporation for separation of water from isopropanol at different temperatures. The results indicated that hydrophilicity and amorphous nature of the membranes were increased with increasing silver nanoparticles in PVA matrix, and permeation flux and selectivity were increased simultaneously. Among the membranes studied, the membrane containing $2.5 \mathrm{wt} \%$ of $\mathrm{Ag}-\mathrm{Nps}$ demonstrated the highest separation selectivity of 634 with a flux of $71.6 \mathrm{~g} \mathrm{~m}^{-2}$ $\mathrm{h}^{-1}$.

Graphene $^{26}$ is a single-layer crystal with honeycomb lattice structure. As a new type of nanomaterial with the thinnest, strongest and thermal conductivity, the research trend of its application value is still in the ascendant. The only one-atom thick and nearly frictionless surface enables graphene to form membranes that minimize transport resistance and maximize permeate flux. Bunch et al. ${ }^{27}$ attributed the ultra-fast transport of water to a low-friction flow of a monolayer of water through 2D capillaries formed by closely spaced graphene sheets and diffusion of other molecules is blocked by reversible narrowing of the capillaries in low humidity and/or by their clogging with water. The graphene-based membranes ${ }^{28}$ could be used as functional membranes for constructing high separation performance, while graphene has strong hydrophobicity and low reactivity and it has certain limitations as pervaporation dehydration membranes. Graphene oxide (GO) is a derivative of graphene, ${ }^{28,29}$ which has a similar two-dimensional structure to graphene. In addition to the six-membered ring skeleton of carbon atoms, it also contains polar oxygen-containing functional groups such as hydroxyl groups, epoxy groups, carboxyl groups, and carbonyl groups. The pioneering work of Geim et $a l .{ }^{30}$ found that submicrometer-thick laminates formed from GO can be completely impermeable to liquids, vapors and gases, yet allow unimpeded permeation of water. Besides, molecular transport within GO-based membranes is particularly benefited by the oxygen atoms bonded to the carbon atoms in the oxidized regions of graphene play the role of spacers that keep graphene planes about 0.7 to $1.0 \mathrm{~nm}$ apart in GO laminates, and the pristine regions create almost frictionless $2 \mathrm{D}$ nanochannels for transporting water molecules across GO laminates. GO exhibits outstanding hydrophilicity and facilitates to further modification attributed to the complex and active structure, thereby preparing nanocomposite membranes with excellent properties. Tang et al. ${ }^{31}$ assembled free-standing GO membranes by pressurized ultrafiltration method, and studied the pervaporation performance of ethanol dehydration. Experimental results suggest that the interlaminar spacing is determined by both packing density of GO nanosheets and water content in the feed solution. By tuning the ultrafiltration pressure, a high separation performance with water permeability of 13800 barrer $\left(1\right.$ barrer $=3.348 \times 10^{-19} \mathrm{kmol} \mathrm{m} \mathrm{m}^{-2}$ $\mathrm{s}^{-1} \mathrm{~Pa}^{-1}$ ) and water/ethanol selectivity of 227 is achieved for dehydration of an $85 \mathrm{wt} \%$ ethanol aqueous solution at $24{ }^{\circ} \mathrm{C}$. The high stability and hydrophilic layered packing structure of the GO sheets and the appropriate layer spacing allow it to preferentially transport water.

In this paper, PVA/GO nanocomposite membranes ${ }^{32-34}$ with different GO content were prepared and analysed by attenuated total reflectance-Fourier transform infrared spectroscopy (ATRFTIR), scanning electron microscopy (SEM), X-ray diffractometry (XRD), and thermogravimetric analysis (TGA), water contact angle (WCA) and degree of swelling. The pervaporation performance of membranes for ethanol dehydration was also tested.

\section{Experimental}

\subsection{Material}

Poly(vinyl alcohol) (PVA) with $M_{\mathrm{w}} \sim 100000$ was obtained from Beijing Organic Chemical Co., Ltd. (Beijing, China). Flake graphite powder (325 mesh) was purchased from Nanjing Xian Feng Nano Material Technology Co., Ltd. (China). Sulfuric acid $\left(\mathrm{H}_{2} \mathrm{SO}_{4},>98 \%\right)$, sodium nitrate $\left(\mathrm{NaNO}_{3}, \mathrm{AR}\right)$ and potassium permanganate $\left(\mathrm{KMnO}_{4},>99 \%\right)$ were supplied by Modern Oriental (Beijing) Technology Development CD., LTD. (Beijing, China). Hydrochloric acid ( $\mathrm{HCl}, \mathrm{AR}$ ) and hydrogen peroxide $\left(\mathrm{H}_{2} \mathrm{O}_{2}, 30\right.$ vol\%) were from Shanghai Jinlu Chemical Co., Ltd. (Shanghai, China). Glutaraldehyde acts (GA, 50\%) was purchased from Tianjin Guangfu Fine Chemical Research 
Institute (China). Acetic acid (HAc, AR) and ethanol (AR) were supplied by Modern Oriental Technology Development Co., Ltd. (Beijing, China).

\subsection{Synthesis of GO}

Graphene oxide was synthesized following the modified Hummers' method. ${ }^{35}$ The steps were as follows: $2.5 \mathrm{~g}$ of $\mathrm{NaNO}_{3}$ and $115 \mathrm{ml}$ of $98 \mathrm{wt} \% \mathrm{H}_{2} \mathrm{SO}_{4}$ were mixed in an ice bath for $10 \mathrm{~min} .5 \mathrm{~g}$ of graphite powder was added and stirred for $1 \mathrm{~h}$. Then $15 \mathrm{~g}$ of $\mathrm{KMnO}_{4}$ was slowly added in batches to keep the temperature under $20^{\circ} \mathrm{C}$. After $1 \mathrm{~h}$, stirring was continued for 2 hours at $35^{\circ} \mathrm{C}$. The temperature of the mixture was adjusted to $98{ }^{\circ} \mathrm{C}$ for $30 \mathrm{~min}$ while $230 \mathrm{ml}$ of deionized water was added continuously. Then stop the reaction with a large amount of deionized water. Added $30 \% \mathrm{H}_{2} \mathrm{O}_{2}$ to the solution, the reaction product was centrifuged and washed deionized water and $5 \%$ $\mathrm{HCl}$ solution repeatedly to remove the metal ions from the product. Then sonicated for $1 \mathrm{~h}$ and freeze-drying to obtain dark brown graphene oxide (GO) powder finally. ${ }^{36}$

\subsection{Fabrication of composite PVA/GO membranes}

The synthesized GO was ultrasonically dispersed in deionized water to prepare GO suspension. PVA powder was dissolved in $2.0 \mathrm{wt} \%$ acetic acid solution, continuously stirred for $2 \mathrm{~h}$ at $90{ }^{\circ} \mathrm{C}$ to obtain PVA solutions.

Different amount of graphene oxide (GO) suspension was added in PVA solutions. The solutions were sonication for 30 min to uniformly disperse GO in the PVA solution. Then, the mixture were stirred in a water bath at $90{ }^{\circ} \mathrm{C}$ for $1 \mathrm{~h}$, and ultrasonic for $30 \mathrm{~min} .2 \mathrm{wt} \%$ glutaraldehyde acts (GA) as a crosslinking agent was added, and stirred for $1 \mathrm{~h}$. Finally, the obtained casting solution was degassed at room temperature. Cut out a certain size of PAN ultrafiltration membrane and tape it to clean and flat glass plates. Then poured PVA/GO casting solution onto the based membranes to cast and then dried for $12-14 \mathrm{~h}$ at room temperature. Finally react at $60^{\circ} \mathrm{C}$ for $1 \mathrm{~h}$ to prepare PVA/GO composite membranes with $0.0 \mathrm{wt} \%, 1.0 \mathrm{wt} \%$, $2.0 \mathrm{wt} \%, 3.0 \mathrm{wt} \%, 4.0 \mathrm{wt} \%$ GO, recorded as GOP-0.0, GOP-0.5, GOP-1.0, GOP-2.0, GOP-3.0, GOP-4.0.

\subsection{Pervaporation performance of composite membranes}

The pervaporation dehydration performance of the PVA/GO composite membranes was assessed on a self-designed stainless steel apparatus in our lab, and flow diagram was illustrated in Fig. 1. The PVA/GO composite membrane was cut and put into the membrane cell (the effective area of the membrane was $2.2 \times 10^{-3} \mathrm{~m}^{2}$ ). The feed tank was heated by electric heating coil and material liquid was pressurized by a magnetic pump from the feed tank (about $2.5 \times 10^{-3} \mathrm{~m}^{3}$ ) to the upper side of the membrane cell under set temperature. The down-stream pressure was maintained at $200 \mathrm{~Pa}$. The permeate component was condensed by liquid nitrogen and collected in the cold trap, and the mass of the permeate component was accurately weighed. Contents of upstream feed solution and downstream permeate, which consisted of ethanol and water, were analysed with the aid of chromatography (Shimadzu, GC-14C, Japan).

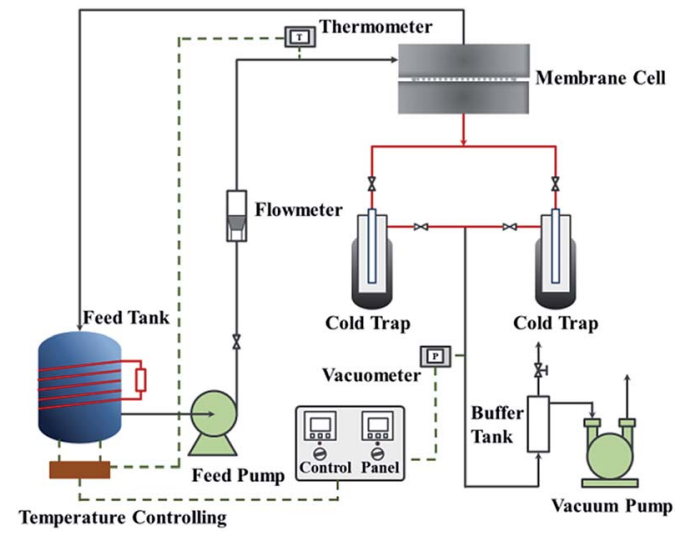

Fig. 1 Flow chart of pervaporation evaluation apparatus.

Pervaporation performances indicators mainly include permeate flux $J$ and separation factor $\alpha$, which are defined as follows:

$$
\begin{gathered}
J=\frac{m}{A \times t} \\
\alpha=\frac{Y_{\mathrm{A}} / Y_{\mathrm{B}}}{X_{\mathrm{A}} / X_{\mathrm{B}}}
\end{gathered}
$$

where $m$ is the mass of permeating mixture $(\mathrm{g}), A$ is the membrane effective surface area $\left(\mathrm{m}^{2}\right), t$ is the collecting time (h), $J$ is the total flux $\left(\mathrm{g} \mathrm{m}^{-2} \mathrm{~h}^{-1}\right), Y_{\mathrm{A}}$ and $Y_{\mathrm{B}}$ are the concentrations (wt\%) of ethanol and water in the permeate respectively. $X_{\mathrm{A}}$ and $X_{\mathrm{B}}$ are the concentrations (wt\%) of ethanol and water in the feed solution respectively, and subscripts A and B represent ethanol and water respectively.

\subsection{Membrane characterization}

The infrared spectra of composite membranes were analysed with Fourier transform infrared spectroscopy (ATR-FTIR, BRUKER TENSOR 27). All samples were collected from a wave number of $700-4000 \mathrm{~cm}^{-1}$ at a resolution of $2.0 \mathrm{~cm}^{-1}$. The diffraction patterns and the orientation of crystalline phases of composite membranes were tested by Bruker D8 ADVANCE Diffractometer (Germany) with $\lambda=1.54 \AA$ in the range $5^{\circ} \leq 2 \theta \leq$ $90^{\circ}$. The exfoliation of GO powder was also investigated via XRD. Surface and cross section images of all types of membranes were observed by scanning electron microscopy (SEM, JSM7401F, Japan). The membranes were first cryogenically fractured in liquid nitrogen bath to expose their crosssections. Prior to the measurement, all samples were adhered to the metal sample stage with a conductive paste and gold (GATAN MODEL-862; JEOL-JHC-1100) was applied under vacuum. Water contact angle (WCA, Model PV-DP) was experimented to show the hydrophobicity and hydrophilicity of composite membrane. In a nitrogen atmosphere, thermogravimetric analysis (TGA, $1600 \mathrm{HT}$, Mettler-Toledo, Switzerland) with a temperature range of $30-700{ }^{\circ} \mathrm{C}$ and a heating rate of $10^{\circ} \mathrm{C} \min ^{-1}$ was used to test the heat resistance and thermal stability of the membrane varies with increasing temperature. 
Swelling tests on the membranes of the GOP membrane were performed gravimetrically.

\section{Results and discussion}

\subsection{Characterization of samples}

The Fourier transform infrared spectroscopy (FTIR) of the composite GOP membranes was analysed, as shown in Fig. 2. There is a broad absorption peak at $3267 \mathrm{~cm}^{-1}$, which is generated by the stretching vibration of the $-\mathrm{OH}$ groups. It could be observed that the peak intensity of the PVA/GO composite membranes here is weaker than that of the pristine PVA membranes (GOP-0.0), and the peak intensity become weaker with increasing GO in PVA matrix, which possible owing to the crosslinking reaction between PVA and GA increases as increasing GO, so the number of $-\mathrm{OH}$ groups decreases. The $\mathrm{C}=\mathrm{O}$ stretching vibration in the carboxyl group is observed at $1709 \mathrm{~cm}^{-1}$, and the absorption peak at $1234 \mathrm{~cm}^{-1}$ is generated by the $\mathrm{C}-\mathrm{O}$ groups stretching vibration. The absorption peak observed at $1090 \mathrm{~cm}^{-1}$ is the asymmetric stretching vibration of $\mathrm{C}-\mathrm{O}-\mathrm{C}$ groups, indicating that the aldehyde groups of GA crosslinked with $-\mathrm{OH}$ groups of $\mathrm{GO}$ and PVA to produce $\mathrm{C}-\mathrm{O}-\mathrm{C}$ bonds. In addition, the peak intensity of the PVA/GO composite membranes is significantly weaker than the PVA membrane at $1090 \mathrm{~cm}^{-1}$, further demonstrating that GO could enhance the crosslinking degree of the composite membranes. The crosslinking density of the composite membrane can be analysed by semi-quantitative analysis of the peak height ratio of $3267 \mathrm{~cm}^{-1}(\mathrm{O}-\mathrm{H})$ and $2940 \mathrm{~cm}^{-1}(\mathrm{C}-\mathrm{H})$ in the infrared spectrum. ${ }^{37}$ It can be seen from Table 2 that with the amount of GO addition increases, the peak height ratio of the composite membrane decreases, indicating that cross linking density of the composite membrane increases with GO content increases. The ATR-FTIR analysis reasonably explains the strong interaction between PVA and GO.



Fig. 2 ATR-FTIR spectra of GOP composite membranes.
PVA is a polymer with high crystallinity, and loading GO into pristine PVA could affect its crystallinity. ${ }^{38}$ XRD patterns of the graphite and GO powder is presented in Fig. 3, and the XRD spectrum of crosslinked composite GOP membranes is shown in Fig. 4. The $d$-spacing of the sheets structure was estimated by the Bragg formula.

From Fig. 3, it was found that graphite showed a strong diffraction peak at $2 \theta=26.67^{\circ}(d$-spacing $=3.34 \AA)$, which indicated a typical two dimensional layer structure of $\mathrm{sp}^{2}$ hybridization. ${ }^{39}$ No diffraction peak appeared at $2 \theta=26.67^{\circ}$ in the graphene oxide XRD pattern, it shows that GO was successfully synthesized and did not contain the graphite. In contrast, GO exhibits a sharp diffraction peak at $2 \theta=10.57^{\circ}$, the layer spacing of GO can be calculated to be $8.36 \AA$, which is increased compared to the layer spacing of graphene (3.34 $\AA$ ). This is due to graphene have a large amount of oxygencontaining functional groups after oxidation, which increases the GO $d$-spacing. According to Fig. 4, the pristine PVA membranes (GOP-0.0) exhibits a strong diffraction peak at $2 \theta=$



Fig. 3 XRD patterns of graphite and GO powder.



Fig. 4 XRD patterns of GOP membranes.

Table 2 The peak height ratio of $3267 \mathrm{~cm}^{-1}$ and $2940 \mathrm{~cm}^{-1}$ in the infrared spectrum of different membranes

\begin{tabular}{|c|c|c|c|c|c|c|}
\hline$h\left(3267 \mathrm{~cm}^{-1}\right) / h\left(2940 \mathrm{~cm}^{-1}\right)$ & 1.384 & 1.360 & 1.334 & 1.312 & 1.282 & 1.255 \\
\hline
\end{tabular}






Fig. 5 The surface $(a-f)$ and cross section $(g-l)$ images of GOP-0.0-GOP-4.0 membranes, respectively.

$19.57^{\circ}$ ( $d$-spacing of $4.53 \AA$ ), which is a semi-crystalline structure and typical orthogonal lattice of PVA. The PVA/GO composite membranes with different GO additions exhibits strong diffraction peaks at $2 \theta=19.54^{\circ}, 19.37^{\circ}, 19.57^{\circ}, 19.46^{\circ}$, and $19.55^{\circ}$, and no diffraction peak appear at $2 \theta=10.57^{\circ}$, possible due to only the small amount of GO is doped in PVA. It could be seen that the diffraction peak intensity of PVA/GO composite membranes are weaker than that of pristine PVA membranes, simultaneously the crystallinity of PVA is declined after GO addition, which indicating that the number of $-\mathrm{OH}$ groups decreases resulting in the peak intensity decreases. Therefore, it can be assumed based on FTIR and XRD spectral data, that the PVA cross-linking by GO occurs according to an acetal reaction mechanism, with ester formation by acid catalysis and temperature.

The surface images and cross-section structures of the composite membranes were observed by scanning electron microscopy (SEM). The SEM images of all type of GOP membranes are shown in the Fig. 5. The surface image of the pristine PVA membrane (Fig. 5a) is flat and almost wrinkle-free, whereas the PVA/GO composite membranes have slight wrinkles, which are typical GO surface wrinkles. With increasing of GO content, the surface unevenness of the PVA/GO composite membranes increases. The cross-section structures of the composite membranes are shown in the Fig. $5 \mathrm{~g}-1$, according to the SEM images, the thickness of composite GOP membranes is

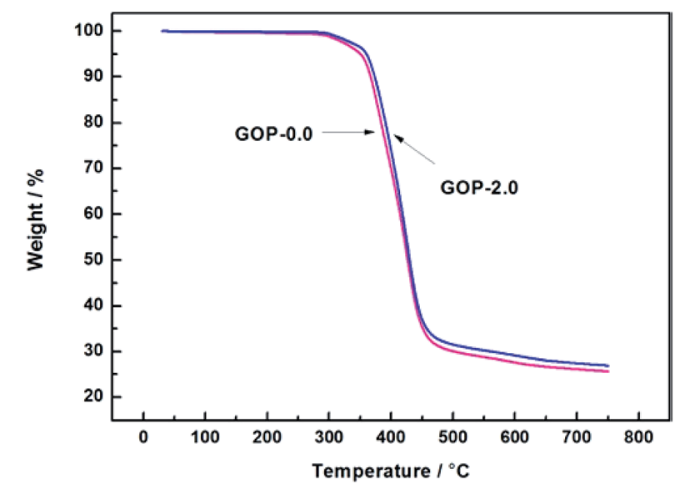

Fig. 6 TGA curves of GOP-0.0 and GOP-2.0 composite membrane. about $8 \mu \mathrm{m}$. Compared with the pristine PVA membranes (Fig. 5g), the separation layer and the support layer of the PVA/ GO composite membranes has a clear boundary line and the pore intrusion phenomenon is limited, while the PVA membranes could observe an pore intrusion.

Thermogravimetric analysis (TGA) indicated that the heat resistance and thermal stability of the polymer vary with increasing temperature. The composite GOP membranes were further characterized using TGA analyses under a nitrogen atmosphere. The results are presented in the Fig. 6 . The initial weight loss both begin at $250{ }^{\circ} \mathrm{C}$, attributed to the evaporation of physically absorbed water molecules in the membranes. The second stage of weight loss are observed at about $360{ }^{\circ} \mathrm{C}$ and $370{ }^{\circ} \mathrm{C}$ for the composite GOP-0.0 membranes and the composite GOP-2.0 membranes respectively. The second stage of weight loss is mainly caused by the volatilization of the main chain of PVA and the degradation of unstable oxygen functional groups of GO. Due to the small amount of GO added and only physical effects occurred between molecules, the two thermogravimetric curves does not show significant differences. The end point weight of composite GOP-2.0 membrane at the second stage is slightly higher, which is due to GO has better thermal stability. However, the weight loss of the composite GOP-2.0 membranes in the second stage occurs at a higher temperature, which indicating that the thermal stability of the separation membranes is slightly improved after GO addition.

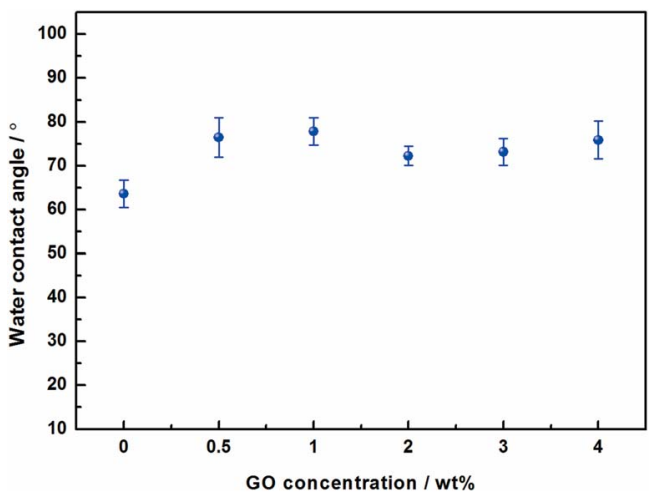

Fig. 7 Water contact angles of PVA/GO membranes with different GO loadings. 


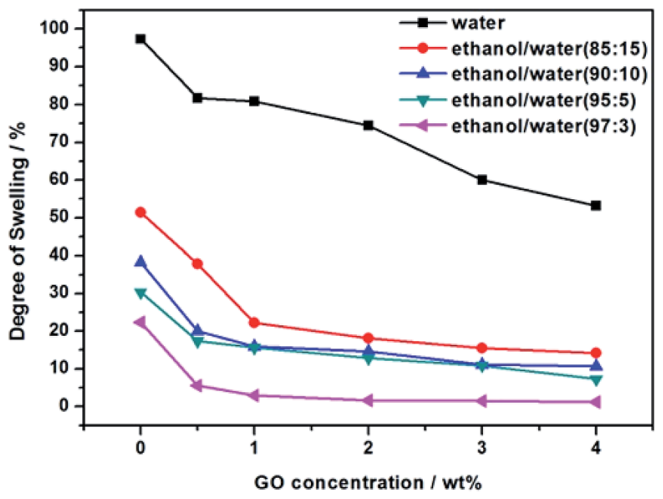

Fig. 8 Swelling degree of GOP membranes with different GO addition.

The effect of the hydrophilicity of the composite membranes with different GO additions was investigated by water contact angle (WCA). As shown in the Fig. 7, the contact angle of the pristine PVA membranes is $63.6^{\circ}$ (average value), whereas the PVA/GO composite membranes with different GO addition are $76.5^{\circ}, 77.8^{\circ}, 72.3^{\circ}, 73.2^{\circ}$ and $75.9^{\circ}$ respectively. It can be observed that the contact angle of the membranes increase, and the hydrophilicity decrease after GO addition. This is due to the increases in the network crosslink density of the system after GO addition, which reduces - $\mathrm{OH}$ groups in the surface, resulting the increasing of contact angle.
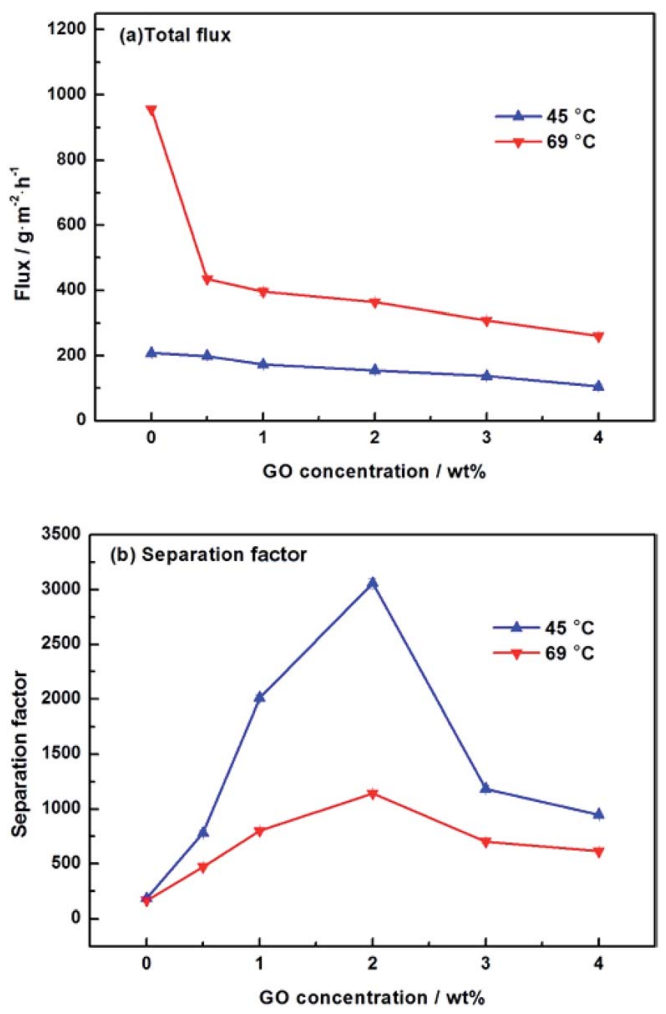

Fig. 9 Pervaporation performance of GOP membranes. (a) Total flux for membranes under varied GO concentration; (b) separation factor for membranes under varied GO concentration.
The swelling test results are shown in Fig. 8, the pre-dried membrane samples were immersed in pure water and different ethanol/water binary solutions, respectively. It can be seen that the degree of swelling of the membranes decreases with the increase of the GO addition amount, it is mainly contributed by the hydrogen bonding between GO and PVA, which enhances the membrane rigidity. In addition, as the concentration of ethanol increases, the degree of swelling decreases.

\subsection{Pervaporation performance for ethanol dehydration}

We further studied the pervaporation performance of the composite GOP membranes at feed concentration is $90 \mathrm{wt} \%$ ethanol and feed temperature of $45^{\circ} \mathrm{C}$ and $69^{\circ} \mathrm{C}$ respectively. As shown in Fig. 9a, the total flux of PVA/GO composite membranes are less than PVA membranes. Although the GO nanosheets layer provide an ultra-fast transport pathway to water, the increase of water contact angle makes water harder to enter in membrane, and the increase of PVA crosslinking degree makes it more difficult for water to pass through the membrane, thus the water flux decrease. As can see from Fig. 9b, the separation factor is very high, and in this case, the total flux is determined by the water flux, so total flux decreases. From Fig. 9b, the separation factors first increases and then decreases with increasing GO. When the GO addition increases from $0.0 \%$ to $2.0 \mathrm{wt} \%$, the separation factor of the membrane increases sharply, which can be attributed to the cross linking reaction between the GO sheet and the PVA matrix, and the cross linking density increases lead to the membrane more dense. For both experimental temperatures, the separation factor reach the highest value when the amount of GO is $2.0 \mathrm{wt} \%$, which is 1143 for $65{ }^{\circ} \mathrm{C}$ and 3059 for $45{ }^{\circ} \mathrm{C}$. Compared with the pristine PVA membranes, the separation factor of all PVA/GO composite membranes are more than 1000 , indicating that GO blending in PVA could significantly enhance the separation factor of the membranes. When GO addition exceed $2.0 \mathrm{wt} \%$, the decrease in the separation factor may be due to the saturation limit of the GO load, and higher than this concentration cause agglomeration of GO, causing defects in the membrane. ${ }^{\mathbf{4 0 - 4 2}}$ The GOP-2.0 membrane is the best selection for further study, due to excellent separation factor and suitable flux. Fig. 10 describes the effect of ethanol concentration on GOP-2.0 performance. According to Fig. 10a, with the increase of ethanol concentration, the total flux decrease notably at experiment temperature, $45^{\circ} \mathrm{C}$ and $69^{\circ} \mathrm{C}$. It is owing to that when the mass percentage of water in the feed liquid is decreased, the degree of swelling of the membrane is reduced and the free volume of the membrane is decreased, so that the transport resistance of water and ethanol is increased. At the same time, it is known from Fig. 11 that the ethanol flux is almost constant and close to zero, while the flux of water is large and the trend is almost similar to the total flux. Since the water is preferentially permeated and the separation factor is large, the total flux is determined by the water flux, so the total flux decreases as the ethanol concentration increases. Otherwise, the separation factors of membranes increases with increasing ethanol concentration 

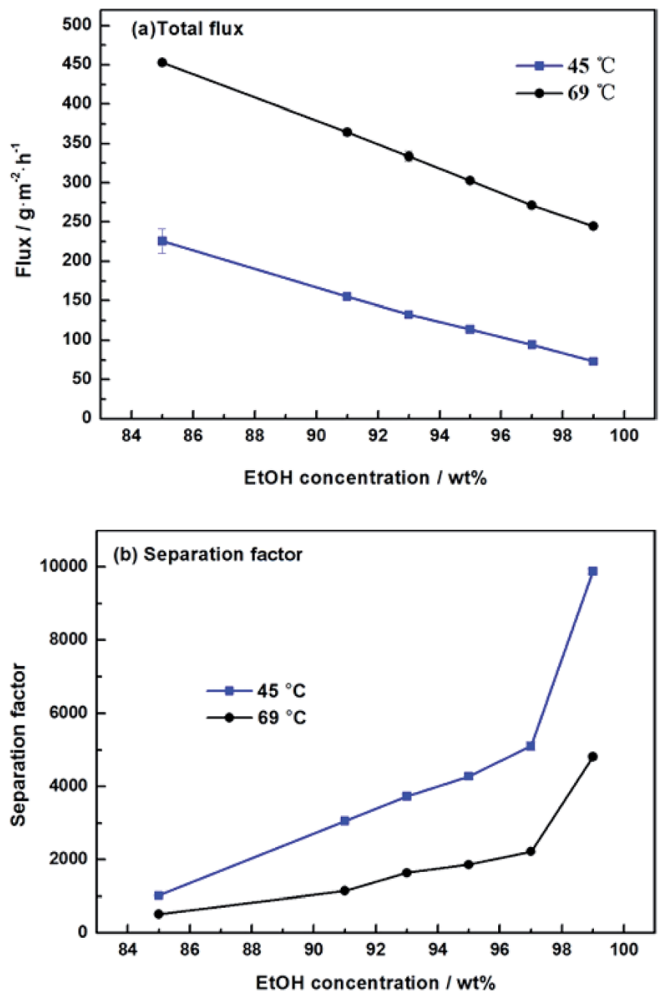

Fig. 10 Pervaporation performance of GOP-2.0 membrane. Total flux (a) and separation factor (b) for membranes under varied ethanol concentration.

(Fig. 10b), especially in the high ethanol concentration. This may be caused by that, when the water concentration decreases, the swelling degree of the membrane also decreases, the chain activity spacing of the polymer become smaller, which makes the ethanol diffuse harder that water for its large size.

Fig. 12 is the effect of operating temperature on pervaporation performance with $90 \mathrm{wt} \%$ ethanol in feed concentration. With the temperature rising from $37{ }^{\circ} \mathrm{C}$ to $69{ }^{\circ} \mathrm{C}$, the total flux of the composite GOP-2.0 membranes increase from $103 \mathrm{~g} \mathrm{~m}^{-2}$ $\mathrm{h}^{-1}$ to $364 \mathrm{~g} \mathrm{~m}^{-2} \mathrm{~h}^{-1}$, and the total flux of the composite GOP0.0 membranes increase from $139 \mathrm{~g} \mathrm{~m}^{-2} \mathrm{~h}^{-1}$ to $956 \mathrm{~g} \mathrm{~m}^{-2} \mathrm{~h}^{-1}$ (Fig. 12a). Temperature is an important factor affecting the total

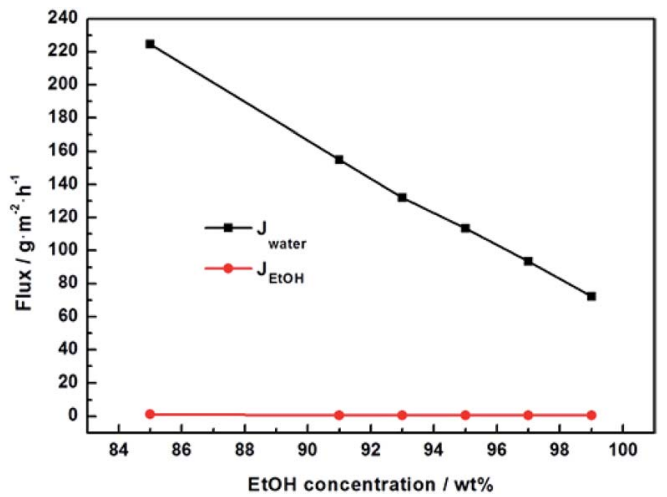

Fig. 11 Pervaporation performance of GOP-2.0 membrane at $45^{\circ} \mathrm{C}$. Water flux and ethanol flux under varied ethanol concentration.
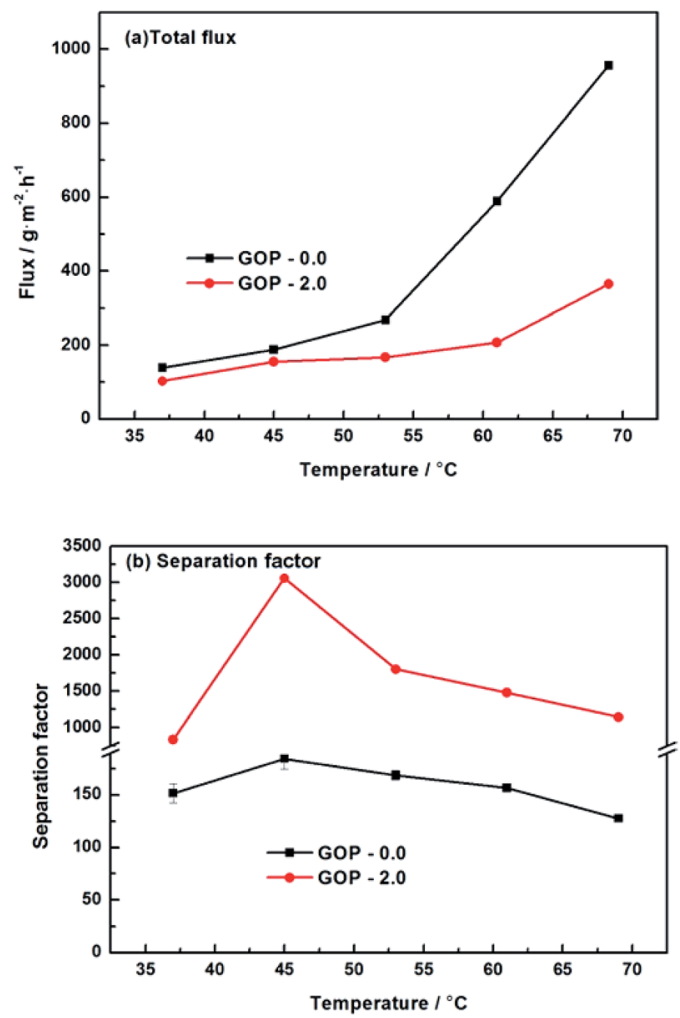

Fig. 12 Pervaporation performance of GOP-2.0 membrane. Total flux (a) and separation factor (b) for membranes under varied temperature.

flux and separation factor. As the feed temperature increases, the vapour pressure in the feed side increases simultaneously and thus the mass transfer driving force of pervaporation increases, which is beneficial to mass transfer. At the same time, the activity and flexibility of the polymer chain are strengthened and the molecular segment spacing increases with increasing temperature, which is benefit for the diffusion of water and ethanol. The above-mentioned combined factors lead to the increase in the total flux. From Fig. 12b, it could be seen that the separation factor first increases and then decreases with increasing temperature. This may be due to when the temperature increases from $37^{\circ} \mathrm{C}$ to $45^{\circ} \mathrm{C}$, the activity of polar groups in the membrane is intense, the permeation rate of water and ethanol molecules increases, and the separation effect is obvious. When the temperature exceeds $45^{\circ} \mathrm{C}$, it may be that during the temperature increases, the membrane structure undergoes subtle changes and the macromolecular segments in the membrane are re-aligned, the free volume of the membrane increases and the permeation resistance of the ethanol molecules decreases lead to the permeation rate of ethanol exceeds the rate of penetration of water, thereby reducing the separation factor. At present, there is no clear rule about the relationship between separation factor and temperature. This phenomenon has also appeared in the previous literature. ${ }^{43}$ Membranes have the best separation factor of 3059 at $45{ }^{\circ} \mathrm{C}$, for the composite GOP-2.0 membranes, much greater than the composite GOP-0.0 membranes (the pristine PVA membranes) in this work, and the PVA membranes obtained in previous studies (Table 3). 
Table 3 Comparison of pervaporation performance of PVA hybrid membranes for ethanol dehydration

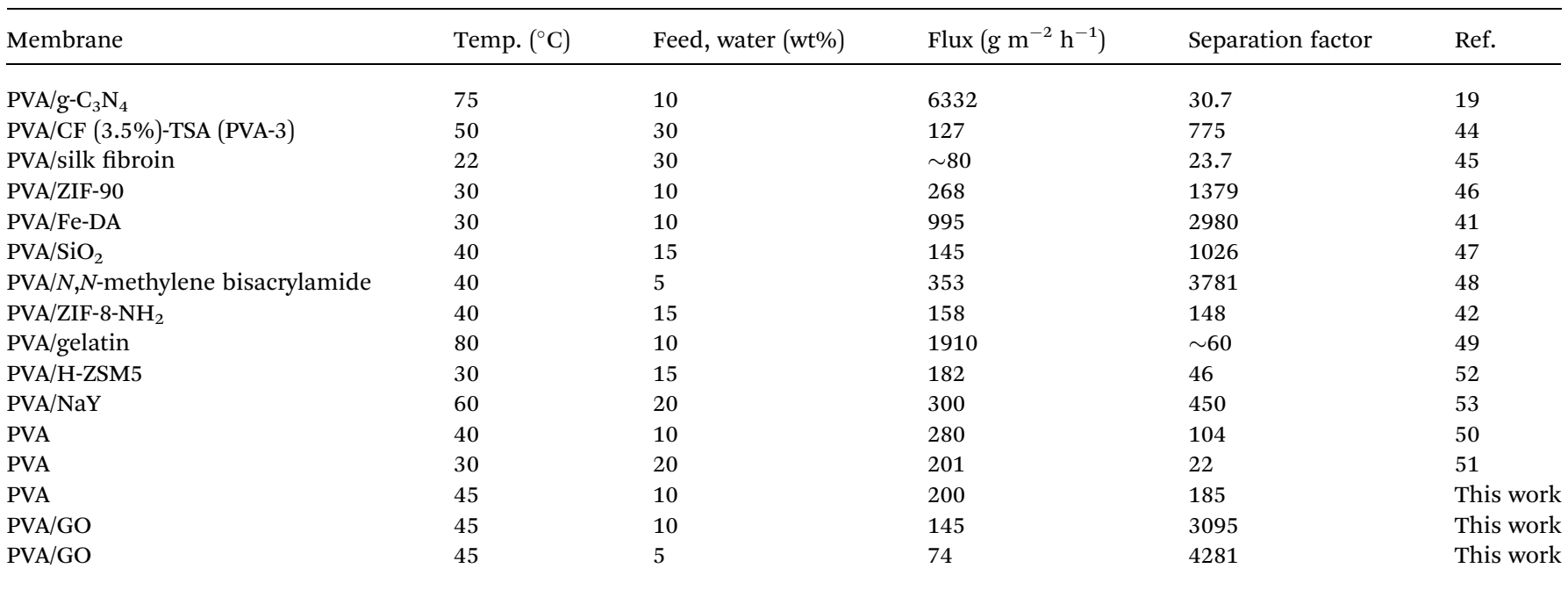

\section{Conclusions}

In this work, PVA/GO nanocomposite membranes were fabricated and used for ethanol dehydration by pervaporation. By GO addition, the crosslinking degree of PVA is effectively increased. When GO content increases from 0.0-4.0 wt\%, the PVA crosslinking degree increases, the total flux of the PVA/GO composite membranes decrease, while the separation factors first increases but then decreases, which may be attributed to defects caused by GO aggregation. Of all the PVA/GO membranes, the composite GOP-2.0 membranes had the best separation performance with the separation factor of 3059 and the total flux of $145 \mathrm{~g} \mathrm{~m}^{-2} \mathrm{~h}^{-1}$ at $45{ }^{\circ} \mathrm{C}$ and $90 \mathrm{wt} \%$ ethanol concentration. The influence of feed concentration and temperature were also conducted. With the increase of feed ethanol concentration, the separation factors of membranes increases significantly, while the total flux decrease. Separation factor 9866 and permeation flux $74 \mathrm{~g} \mathrm{~m}^{-2} \mathrm{~h}^{-1}$ was observed at $45{ }^{\circ} \mathrm{C}$ and $99 \mathrm{wt} \%$ ethanol concentration. Total flux increase with feed temperature, while separation factor increase first and then decrease. Compared with pristine PVA membranes, permeate flux of PVA/GO nanocomposite membranes decreased a certain amount, but the separation factor were notably increased.

\section{Conflicts of interest}

There are no conflicts to declare.

\section{Acknowledgements}

The authors greatly appreciate the financial supports of National Natural Science Foundation of China (21736001, 21776153, and 21576150).

\section{References}

1 C. A. Cardona and O. J. Sanchez, Bioresour. Technol., 2007, 98, 2415-2457.
2 B. Bolto, M. Hoang and Z. Xie, Chem. Eng. Process., 2011, 50, 227-235.

3 R. W. Baker, Membr. Technol. and Appli., Wiley, 2012, pp. 3771-3777.

4 P. A. Kober, J. Am. Chem. Soc., 1917, 39, 944-948.

5 Y. Sakurada, A. Sueoka and M. Kawahashi, Polym. J., 1987, 19, 501-503.

6 S. Qiu, L. Wu and G. Shi, Ind. Eng. Chem. Res., 2010, 49, 11667-11675.

7 M. D. Kurkuri, U. S. Toti and T. M. Aminabhavi, J. Appl. Polym. Sci., 2002, 86, 3642-3651.

8 K. S. V. K. Rao, M. C. S. Subha, M. Sairam, N. N. Mallikarjuna and T. M. Aminabhavi, J. Appl. Polym. Sci., 2007, 103, 19181926.

9 Z. Gao, Y. Yue and W. Li, Zeolites, 1996, 16, 70-74.

10 N. Durmaz-Hilmioglu, A. E. Yildirim, A. S. Sakaoglu and S. Tulbentci, Chem. Eng. Sci., 2001, 40, 263-267.

11 T. A. Aminabhavi and H. G. Naik, J. Appl. Polym. Sci., 2002, 83, 244-258.

12 N. Isiklan and O. Sanli, Chem. Eng. Process., 2005, 44, 10191027.

13 M. Rafik, A. Mas, M. F. Guimon, C. Guimon, A. Elharfi and F. Schue, Polym. Int., 2003, 52, 1222-1229.

14 M. L. Gimenes, L. Liu and X. Feng, J. Membr. Sci., 2007, 295, 71-79.

15 B. V. K. Naidua, M. Sairam, K. Raju and T. M. Aminabhavi, J. Membr. Sci., 2005, 260, 142-155.

16 S. P. Doguparthy, J. Membr. Sci., 2001, 185, 201-205.

17 Z. Arif, N. K. Sethy, P. K. Mishra, S. N. Upadhayay and B. Verma, J. Porous Mater., 2018, 25, 1203-1211.

18 Y. P. Wu, Z. L. Xie, D. Ng, S. Shen and Z. H. Zhou, J. Appl. Polym. Sci., 2017, 134.

19 D. Liu, Y. Zhang, J. Jiang, X. Wang, C. Zhang and X. Gu, RSC $A d v .$, 2015, 5, 95866-95871.

20 I. Soroko and A. Livingston, J. Membr. Sci., 2009, 343, 189198.

21 J. Wang, M. Li, S.-Y. Zhou, A. Xue, Y. Zhang, Y.-J. Zhao and J. Zhong, Chem. Eng. Sci., 2018, 181, 237-250. 
22 J. Wang, M. Li, S. Zhou, A. Xue, Y. Zhang, Y. Zhao, J. Zhong and Q. Zhang, Sep. Purif. Technol., 2017, 188, 24-37.

23 P. I. Cheng, P. D. Hong, K. R. Lee, J. Y. Lai and Y. L. Tsai, J. Membr. Sci., 2018, 564, 926-934.

24 D. Wang, Q. Lu, M. Wei and E. Guo, J. Appl. Polym. Sci., 2018, 135.

25 H. G. Premakshi, A. M. Sajjan, A. A. Kittur and M. Y. Kariduraganavar, J. Appl. Polym. Sci., 2015, 132.

26 A. K. Geim, Science, 2009, 324, 1530-1534.

27 J. S. Bunch, S. S. Verbridge, J. S. Alden, A. M. van der Zande, J. M. Parpia, H. G. Craighead and P. L. McEuen, Nano Lett., 2008, 8, 2458-2462.

28 A. K. Geim and K. S. Novoselov, Nat. Mater., 2007, 6, 183-191.

29 G. Liu, W. Jin and N. Xu, Chem. Soc. Rev., 2015, 44, 50165030.

30 R. R. Nair, H. A. Wu, P. N. Jayaram, I. V. Grigorieva and A. K. Geim, Science, 2012, 335, 442-444.

31 Y. P. Tang, D. R. Paul and T. S. Chung, J. Membr. Sci., 2014, 458, 199-208.

32 S. Mallakpour, A. Abdolmaleki and Z. Khalesi, Polym. Bull., 2018, 75, 1473-1486.

33 H. K. Dave and K. Nath, J. Water Process Eng., 2016, 14, 124134.

34 R. L. G. Lecaros, G. E. J. Mendoza, W.-S. Hung, Q.-F. An, A. R. Caparanga, H.-A. Tsai, C.-C. Hu, K.-R. Lee and J.-Y. Lai, Carbon, 2017, 123, 660-667.

35 W. S. Hummers and R. E. Offeman, J. Am. Chem. Soc., 1958, 80, 1339.

36 C.-H. Tsou, Q.-F. An, S.-C. Lo, M. De Guzman, W.-S. Hung, C.-C. Hu, K.-R. Lee and J.-Y. Lai, J. Membr. Sci., 2015, 477, 93-100.

37 N. A. Peppas, Makromol. Chem., 1977, 178, 595-601.

38 D. Chen, X. Wang, T. Liu, X. Wang and J. Li, J. Am. Chem. Soc., 2010, 2, 2005-2011.
39 C.-H. Tsou, Q.-F. An, S.-C. Lo, M. De Guzman, W.-S. Hung, C.-C. Hu, K.-R. Lee and J.-Y. Lai, J. Membr. Sci., 2015, 477, 93-100.

40 S. P. Dharupaneedi, R. V. Anjanapura, J. M. Han and T. M. Aminabhavi, Ind. Eng. Chem. Res., 2014, 53, 1447414484.

41 Q. Liu, H. Wang, C. Wu, Z. Wei and H. Wang, Sep. Purif. Technol., 2017, 188, 282-292.

42 H. Zhang and Y. Wang, AIChE J., 2016, 62, 1728-1739.

43 G. Zhang, W. Gu, S. Ji, Z. Liu, Y. Peng and Z. Wang, J. Membr. Sci., 2006, 280, 727-733.

44 A. V. Penkova, M. E. Dmitrenko, N. A. Savon, A. B. Missyul, A. S. Mazur, A. I. Kuzminova, A. A. Zolotarev, V. Mikhailovskii, E. Landeranta, D. A. Markelov, K. N. Semenov and S. S. Ermakov, Sep. Purif. Technol., 2018, 204, 1-12.

45 J. R. Karp, F. Hamerski and V. R. Silva, Polym. Eng. Sci., 2018, 58, 1879-1887.

46 Z. Wei, Q. Liu, C. Wu, H. Wang and H. Wang, Sep. Purif. Technol., 2018, 201, 256-267.

47 L. L. Xia, C. L. Li and Y. Wang, J. Membr. Sci., 2016, 498, 263275.

48 J. Li, L. Zhang, J. Gu, Y. Sun and X. Ji, RSC Adv., 2015, 5, 19859-19864.

49 H. Wu, X. Lu, X. Li, Y. Li, C. Zhao and Z. Jiang, Chin. J. Chem. Eng., 2014, 22, 19-27.

50 C. K. Yeom, S. H. Lee and J. M. Lee, J. Appl. Polym. Sci., 2001, 79, 703-713.

51 B. V. Di Carlo and A. C. Habert, J. Mater. Sci., 2013, 48, 14571464.

52 D. P. Suhas, T. M. Aminabhavi and A. V. Raghu, Polym. Eng. Sci., 2014, 54, 1774-1782.

53 Z. Huang, H. M. Guan, W. L. Tan, X. Y. Qiao and S. Kulprathipanja, J. Membr. Sci., 2006, 276, 260-271. 